\title{
The Allen-Unger Global Commodity Prices Database
}

\section{Social and Economic History}

\author{
R. C. Allen \\ New York University Abu Dhabi, United Arab Emirates \\ bob.allen@nuffield.ox.ac.uk \\ R. W. Unger \\ University of British Columbia, Vancouver, Canada \\ richard.unger@ubc.ca
}

\begin{abstract}
The Allen-Unger Database contains price series for commodities from locations in Europe from the late Middle Ages to 1914 and also from cities in the Americas, the Middle East and the Far East. It is also possible to search for series by date range, location and commodity or any combination of the three. Data are reported in Excel spreadsheets with the files downloadable. The Database serves as a useful tool for various forms of research in economic history and in social history with the information presented in an easily accessible and flexible format. The data are available at three different sites, each with its own unique features and advantages.
\end{abstract}

\section{Keywords}

prices - commodities - downloadable

- Related data set "Allen Unger Commodities Dataset" with DoI https://doi. org/10.17026/dans-zsu-xavf in repository "DANs" 


\section{Introduction}

Talking about the prices of purchases has a long history and it continues to be a popular subject of conversation among consumers. The topic has played a central role in the study of the economy both contemporary and historic. The cost of living for people has been a necessary component of any assessment of welfare. Knowledge of prices is critical to any effort to explore consumption patterns. Over time prices also reflect the shifting importance to buyers and to societies of specific goods and resources. Many components of economic history, then, rely in one way or another on price data.

Collecting information about price levels, other than simple anecdotal mention, appeared as early as the Middle Ages. In some cases towns charged certain civic officials responsible for overseeing markets to record prices. The goal was to identify possible problems for residents, both sellers and buyers, and to uncover potential violations of rules in place to prevent any one seller from gaining an advantage. In the seventeenth century thinkers about how society functioned generated a more general interest in any consistent patterns in the economy and so they turned attention to what happened to prices. Data collection became more organized and serious in the eighteenth century and by the late nineteenth it was systematic, often by then in the hands of government offices with responsibility for collecting statistics.

While antiquarians may have been gathering bits of data over the long term, the civic and national records grew out of a desire to have data for informed policy formation. In England, Thomas Tooke (1794-1858) in 1838 published the first of six volumes, the last two done with William Newmarch (1830-1882), reporting prices since 1793 . He was concerned about what was the optimal government monetary policy, believing that the supply of money had a deep influence on prices. The figures he and his co-author collected led him to change his views and suggested there was considerable value in gathering data and making that data available. The orderly and purposeful publication of price figures over the longer term grew out of the study of political economy and liberal politics in the second half of the nineteenth century. In at least one case, viz. the exhaustive work of the English social reformer J.E. Thorold Rogers (1823-1890), the series stretched back to the thirteenth century. Work like that of Rogers had been preceded by governments collecting prices in foreign ports, an outgrowth of the consular services that emerged in the early modern Mediterranean and spread much more widely in the eighteenth century. The state needed the data for assessing possible export markets for domestic goods. The plan was to make the information available to producers and traders at home. More generally as time passed the goal of governments was to gain 
knowledge about the broad state of the domestic as well as the international economy and then, in the next step, to establish some sense of the welfare of their populations.

By the beginning of World War I many if not most European national and imperial governments were producing a mass of data which various state offices, some devoted to creating useful statistics, made widely available. For the years before 1914 price data were published in various venues and in various contexts. Contemporary or earlier series, recorded by local officials or interested parties, often remained stored in archives. Because of the diversity of sources and diversity in the ways the figures were gathered the nature and character of the data was also diverse. In the late 1920s a group of scholars set up the International Commission of Price History to make a more systematic effort to collect archival data and publish them. The members of the Commission gathered figures from various sources and from various places, mostly cities, within Europe and the USA. Often it was purchases by continuing institutions such as hospitals, monasteries, schools, colleges or civic governments which allowed the creation of long series of prices, but that only for some commodities. The Commission members produced a series of works in the 1930s and 1940s reporting what they had found (Cole \& Crandall, 1964; Elsas, 1936; Hamilton, 1947; Pelc, 1937; Posthumus, 1946). They inspired later and even more ambitious projects to collect and publish price data (Jorberg, 1972; Gerhard, Kaufhold, \& Fricke-Drewitz, 1990). Originally overwhelmingly European, research in price series has recently expanded to include the New World, the Far East and the Middle East.

The purpose of mounting our database of prices was to make what material had been published with data from the high Middle Ages to 1914 available in machine-readable form, to make the mass of figures, gathered by scholars in the past and already in print form, accessible and easy to use. This dataset is designed to provide figures in the years before state authorities became consistent suppliers of statistics on prices. Because the original sources vary widely in their character and since different scholars, and their assistants, gathered and interpreted the collected numbers in different ways there is the possibility of inconsistency, so perhaps undermining comparability. The International Commission of Price History did set standards for participants to follow which mitigates the implied danger of the prices being not as comparable as might be wanted. The collectors took their numbers from records of institutional buyers, from market reports of wholesale prices, from retail sales and from any other available source. Data are rare, especially for the Middle Ages and the Renaissance, so what was available determined the character of the source. Collection and publication of price series continues with results often available in 
machine-readable form immediately. There was no need, then, to include such recently available series in this database.

\section{Discussion of the Research Problem}

The global commdity prices database is a useful tool for dealing with many questions about the history of the economy and society. In combination with figures on quantities of goods traded it offers a basis for attacking balance of payments questions. Price data form the raw material for almost all of the methods of measuring market integration. More recently the time series have been combined with information on consumption to generate estimates of real incomes over the long term in various parts of the world (Braudel \& Spooner, 1967; Allen, 2009, 2001; Allen, Murphy, \& Schneider, 2012). The database supplies a basis for assessing the comparative performance of economies and the ability of those economies to make life better for people. The database is a highly flexible source with 192 different towns or regions and 165 commodities covering the years from 1237 to 1914 with well in excess of 125,000 data points. There are many gaps in series with prices for only short periods for some goods. Some places have very few observations for perhaps only one good. Some places have prices for a dozen or more commodities and with series running for centuries. While grain prices, for example, come from a number of sites, for less widely traded commodities or ones produced only regionally there are data from very few locations.

The dataset reports the statistics by location and commodity in the original measures, that is the form of payment and the unit sold as stated in the archival sources and reported by those who collected the figures. The numbers are made comparable over time and between or among locations by converting all prices to silver equivalents per unit in the metric system. The conversion involved standardizing the unit of sale to a weight in kilograms or volume in litres. It also involved standardizing coinage to grams of silver or equivalent, the quantities of silver in coins used to pay for goods based on prevailing mint standards at the time of sale. The process of conversion is transparent in the columns of the tables which also give the source of each of the observations. Separate additional files under "Measures" elsewhere in the sites where the data are stored give the conversion factors used for original measures of weight and volume. Additionally, under "Currencies" files report the conversion rates of original coins into quantities of silver for each medium of exchange which turns up in any of the files in the database.

The dataset is available in DANs, the Allen Unger Commodities Dataset being at https://doi.org/10.17026/dans-zsu-xavf. There all of the prices with 


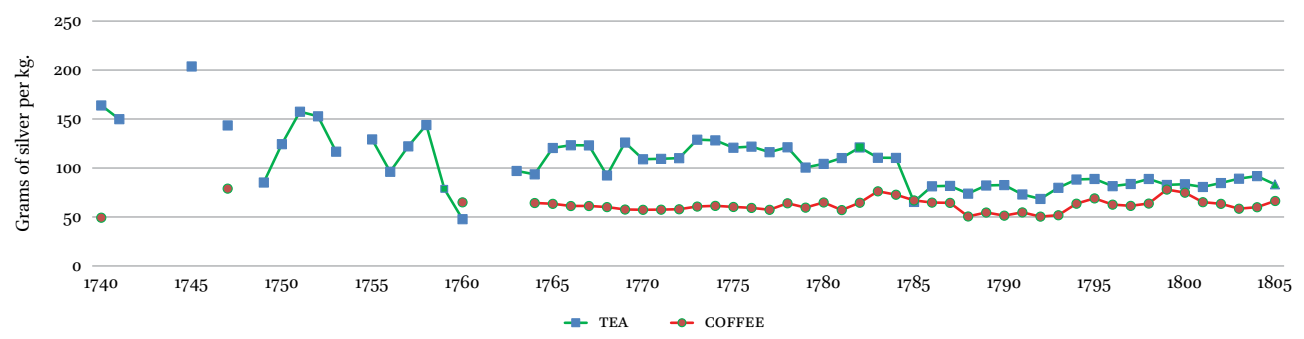

FIGURE 1 Prices of Tea and Coffee, 1740-1805 in England, grams of silver per kg. Explanation: Sorting the commodity file alphabetically makes easy finding English coffee prices which begin to appear in 1682 and, with breaks, run to 1869 . Doing the same for tea shows English prices starting at 1673 and, with breaks, ending in 1869. Copying and pasting the series of prices in grams of silver per kilogram, it is possible to create a comparison of the prices of the two drinks in the eighteenth century when there was competition between them. The resulting graph shows that coffee prices were generally stable and that tea, because less was needed to make a cup of the drink, was always substantially cheaper per cup. Still with the two series side by side calculating the correlation coefficient is simple. It is an insignificant 0.0026 .

conversion factors and sources are given in one large file. The data are also available from two other websites. One is among the Datafiles of Historical Prices and Wages maintained at the International Institute of Social History (http://www.iisg.nl/hpw/data.php). At this website, rather than one large file, there is a separate file for each commodity in each location. It is then possible to select files for individual commodities or individual cities. The version of the database at http://www.gcpdb.info/index.html offers not only the ability to download individual files for a commodity but also to create custom files using filters for a specific good, market and time period and any combination of the three. There are also maps of different continents with the sites for which there are series in the database identified. Dropdown menus for each location allow selection of the relevant commodity or commodities and then downloading the chosen data, in .csv format (derived from the original Excel spreadsheet files).

\section{Methods of Data Gathering and Analysis}

The series posted in the dataset come from price data gathered over the past two centuries with concentration on data made available through publication to a wider public from the 1930 s on. Though a few of the series in the dataset are the results of recent archival work the overwhelming majority are from published sources. The series are presented as Excel files. Users are given the option of downloading any individual series or groups of series except with 


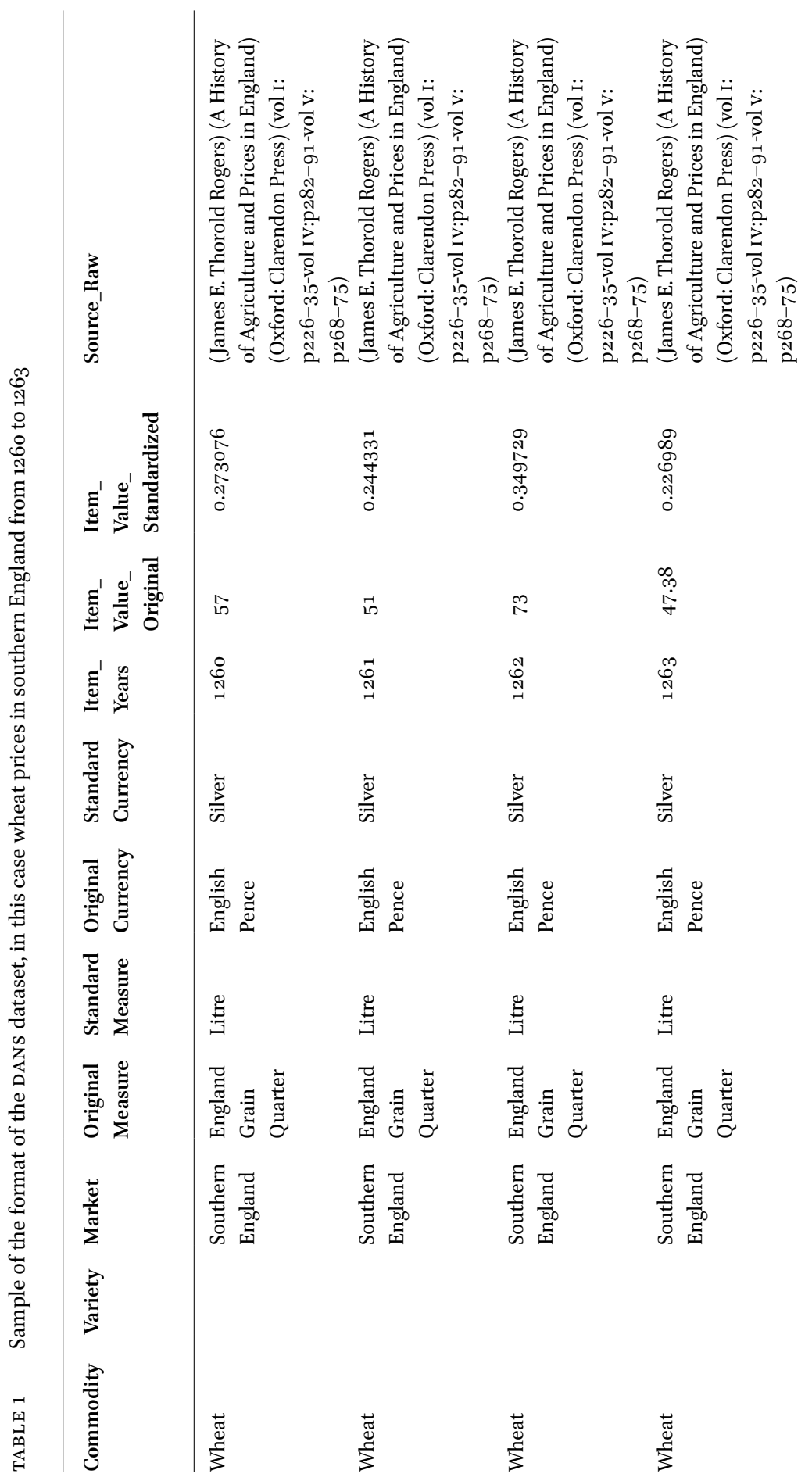


DANS where all price data are in one file. A desired and selected body of data can be created by doing relevant searches which will produce one spreadsheet with all requested figures. In all cases files give a single set of prices for goods at a location with the source, dates, units in the original, prices in the original, rates of conversion of both of those, and the resulting prices in grams of silver per kilogram. The data in a downloaded file can be manipulated, compared with other series and easily presented in the most effective form for whatever purpose it is being used. The analysis of the numbers is left to the user, the options and possible applications being Brobdingnagian. In the current form the files are highly flexible and useable for a broad range of studies. On the smallest scale it is possible to find specific figures for specific years in specific places, so it is possible to say what an individual had to part with in order to fulfill demand for many goods in many places. The most complete and comprehensive data not surprisingly come from the eighteenth and nineteenth centuries. On a larger scale it is possible to make comparisons between or among markets from the late Middle Ages to 1914. It is possible to examine the cost relationship of goods at any point in time or over time, indicating how one of them might have competed with or replaced another. If wage data are available, then it is possible to measure what individuals could buy with their incomes. Prices are reported, as with the standards of the International Commission for Price History, by year. These can be based on an average of the observations available with the number of those observations varying. Changes within the year are not reflected in the figures. However, gaps created by a lack of data are reflected. Not all published prices are included, but the website http://www. gcpdb.info/index.html offers a function allowing the uploading of additional data and any user is welcome to submit a series which is absent from the current dataset. The reporting on all three sites has been subject to recent revision to isolate potential errors and inconsistencies. In all cases the reported figures rely on those who originally gathered the data and published it. Since there are so many prices and over such a long period of time, some surprises are to be expected, such as wide swings from one year to the next, which reflect the nature of economies in the period covered.

4. Description of the Data Set

- Allen Unger Commodities Dataset deposited at DANS - Dor:https://doi .org/10.17026/dans-zsu-xavf

- Allen-Unger Global Commodity Prices Dataset deposited at the International Institute of Social History - URL: www.iisg.nl/hpw/data.php 
- Allen-Unger Global Commodity Prices Database deposited at a dedicated website - URL: www.gcpdb.info

- Temporal coverage: late Middle Ages-1914

In DANS, the Allen Unger Commodities Dataset (https://doi.org/10.17026/danszsu-xavf) has an overview, a description of the material in the dataset and four data files: commodities, currencies, measures and a text file describing the material along with a list of the sources used in creating the dataset. Currencies and Measures give the bases for the conversions to produce prices for a standard quantity in grams of silver. The Commodities file is the largest $(36,6 \mathrm{Mb})$. The categories of the columns in the file are the commodity, its variety giving more detail about the good where relevant, the market which is the town or region, the original measure used in that market, the standard measure to which it is converted such as a kilogram or a litre, the original currency used in its sale, the standard currency to which it is converted for the sake of comparison, the year of the observation, the original value, its standardized value in grams of silver per unit of measure, any relevant notes and the source of the original data. The commodities, measures and currencies files when downloaded will come in Text (Tab delimited) form with all information in one column. All the information will be strung together in the first cell. If using Microsoft Excel by highlighting the initial column, going to the Data tab and clicking on the "Text to Columns" icon the wizard will appear. Clicking on "delimited", then clicking on "Next", then clicking on "comma" and then "Finish" the information will appear in separated columns in each row. Using the search features of Excel makes it possible to identify specific data that might prove of interest and also to extract distinct series in the massive file to create smaller more manageable files of series for specific commodities, years and places, for example. The commodities data using Excel functions can be sorted by name of the good, the market or the year to isolate and extract more easily manipulated subsets.

\section{Concluding Remarks}

The web site www.gcpdb.info is still and will remain in development as researchers publish new data and more figures become available for mounting in the current format. The database is now complemented by other sites which provide some of the same and more or less the same information but which also add different series. It is anticipated that the files available and included in the current database will be incorporated at some point in a larger database 


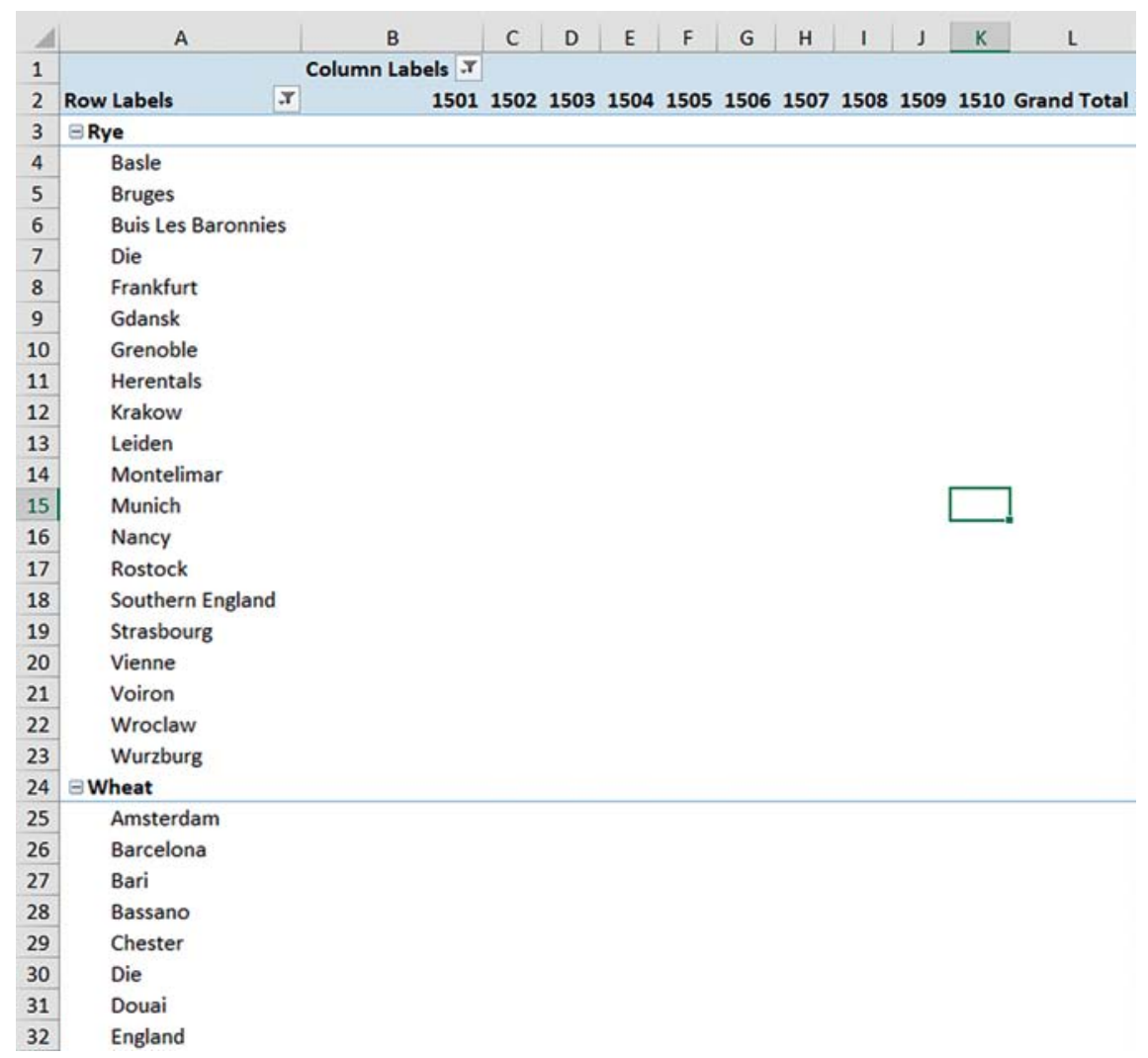

FIGURE 2 Using functions of Excel, lists can be generated of which sites have prices for which years. In this case the table indicates the locations with data reported for prices of two major grains, rye and wheat, in any of the years in the first decade of the sixteenth century. Clicking on one of the empty table cells bring up a new table with the desired information and its source.

or databases. That will go even further in fulfilling the original goal of making price data series easily accessible to researchers everywhere all the time and in a user-friendly form, complete with full documentation of sources and in a form where figures can be manipulated in any way they might be useful for analysis and/or presentation.

\section{References}

Allen, R. C. (2001). The Great Divergence in European Wages and Prices from the Middle Ages to the First World War. Explorations in Economic History, 38(4), 411-447. 
Allen, R. (2009). Agricultural Productivity and Rural Incomes in England and the Yangtze Delta, c. 1620-c. 1820. The Economic History Review, 62(3), new series, 525-550. Retrieved from https://www.jstor.org/stable/20542958.

Allen, R., Murphy, T., \& Schneider, E. (2012). The Colonial Origins of the Divergence in the Americas: A Labor Market Approach. The Journal of Economic History, 72(4), 863-894. Retrieved from http://www.jstor.org/stable/41811357.

Braudel, F., \& Spooner, F. (1967). Prices in Europe from 1450 to 1750. In E.E. Rich \& C. Wilson (Eds.), The Cambridge Economic History of Europe, Volume IV: The Economy of Expanding Europe in the Sixteenth and Seventeenth Centuries (pp. 378-485). Cambridge: Cambridge University Press.

Cole, A. H., \& Crandall, R. (1964). The International Scientific Committee on Price History. Journal of Economic History, 24(3), 381-388.

Elsas, M. J. (1936). Umriss einer Geschichte der Preise und Löhne in Deutschland. 3 vols. Leiden: A. W. Sijthoff.

Hamilton, E. J. (1947). War and Prices in Spain, 1651-180o. Harvard Economic Studies. Cambridge: Harvard University Press.

Pelc, J. (1937). Ceny W Gdansku w XVI i XVII Wieku. Lwow.

Posthumus, N. W. (1946). Inquiry into the History of Prices in Holland. Publications of the International Scientific Committee on Price History. Leiden: E.J. Brill. 